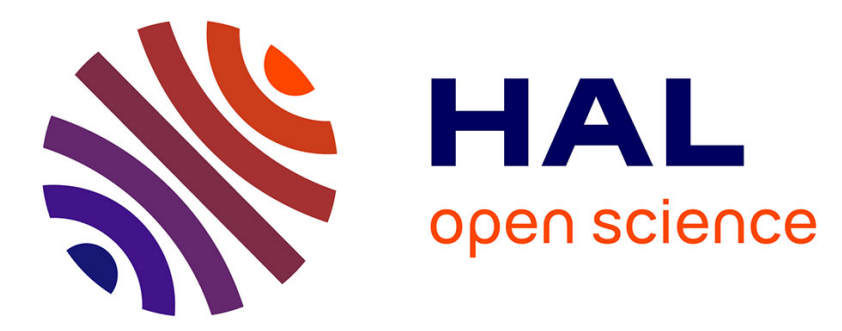

\title{
Designing a stacked three-element parasitic superdirective antenna
}

\author{
Abdullah Haskou, Ala Sharaiha, Sylvain Collardey
}

\section{To cite this version:}

Abdullah Haskou, Ala Sharaiha, Sylvain Collardey. Designing a stacked three-element parasitic superdirective antenna. 17th International Symposium on Antenna Technology and Applied Electromagnetics, Jul 2016, Montréal, Canada. 10.1109/ANTEM.2016.7550103 . hal-01357553

\section{HAL Id: hal-01357553 \\ https://hal.science/hal-01357553}

Submitted on 31 Aug 2016

HAL is a multi-disciplinary open access archive for the deposit and dissemination of scientific research documents, whether they are published or not. The documents may come from teaching and research institutions in France or abroad, or from public or private research centers.
L'archive ouverte pluridisciplinaire $\mathbf{H A L}$, est destinée au dépôt et à la diffusion de documents scientifiques de niveau recherche, publiés ou non, émanant des établissements d'enseignement et de recherche français ou étrangers, des laboratoires publics ou privés. 


\title{
Designing a Stacked Three-Element Parasitic Superdirective Antenna
}

\author{
Abdullah Haskou, Ala Sharaiha, and Sylvain Collardey \\ IETR UMR CNRS 6164- Université de Rennes 1, Rennes, France \\ abdullah.haskou@univ-rennes1.fr, ala.sharaiha@univ-rennes1.fr, sylvain.collardey@univ-rennes1.fr
}

\begin{abstract}
In this paper we investigate designing a stacked three-element antenna arrays for UHF band. The array is based on miniaturized printed half-loop antenna integrated in a PCB of $8 \times 8 \mathrm{~cm}^{2}$. To study the inter-element distance effect on the antenna performance (directivity, input impedance and radiation efficiency), a parametric analysis is performed. The obtained results show that for small distances high directivities can be achieved in the case of the fully driven element. However, to transform this array to a parasitic (loaded) one, negative resistances are required and neglecting these resistances significantly decrease the antenna directivity. The results are validated via measurements.
\end{abstract}

Keywords-Superdirectivity, parasitic-element, directivity, radiation efficiency

\section{INTRODUCTION}

Superdirective antenna arrays satisfy both the miniaturization- and high directivity- criteria required in most of the modern wireless applications. Since the first practical validation of such arrays by Altshuler et al [1], a considerable research was done in this domain. In analogy to Yagi antenna, early works were based on wire-type antennas [2]-[5]. Recent works are based on printed antennas (due to their attractive characteristics) [6]-[10]. In this paper, we investigate designing a stacked three-element parasitic superdirective antenna array. The main tradeoffs between the antenna directivity, efficiency, and dimensions are detailed.

\section{Proposed Antenna Design}

The design methodology of superdirective antenna arrays detailed in [10] was used to develop a three-element array. The unit-element used in this array is a miniaturized half-loop antenna printed on a $0.8 \mathrm{~mm}$-thick Rogers RO4003 substrate and integrated in a PCB of $8 \times 8 \mathrm{~cm}^{2}$. It has a simulated (ANSYS HFSS [11]) resonance frequency around $864 \mathrm{MHz}$. The antenna size factor is $k a=1$, where $k=2 \pi / \lambda$ and $a$ is the radius of the smallest sphere enclosing the antenna. The antenna has a directivity of $2.4 \mathrm{dBi}$ and radiation efficiency of $89.4 \%$. The proposed antenna geometry is shown in Fig. 1(a). The inter-element distance $d_{1}$ is varied from $0.69 \mathrm{~cm}$ to $6 \mathrm{~cm}$ to investigate its effect on the antenna input reflection coefficient (Fig. 1(b)), maximum directivity (Fig. 1(c)) and radiation efficiency (Fig. 1(d)). For very small distances the antenna resonance is shifted to $926 \mathrm{MHz}$. As the distance increases this resonance approaches the one of the unit-element. As for

\footnotetext{
${ }^{1}$ This work was done with the funding of the French National Research Agency as part of the project "SOCRATE" and the support of the "Images et Reseaux" cluster of Brittany region, France.
}

the maximum directivity, we see that starting from an interelement distance of $d_{1}=3.5 \mathrm{~cm}$ interesting directivities can be attained in the case of the fully-driven array. However, in the case of the parasitic array, some negative resistances are required, and neglecting these resistances significantly decreases the attained directivity. As for the parasitic array radiation efficiency, it increases when the inter-element distance exceed $3 \mathrm{~cm}(0.1 \lambda)$.

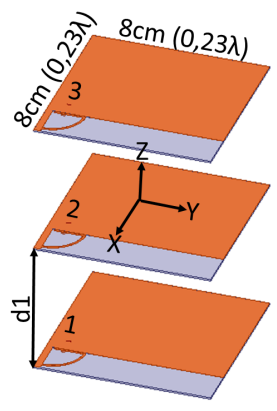

(a)

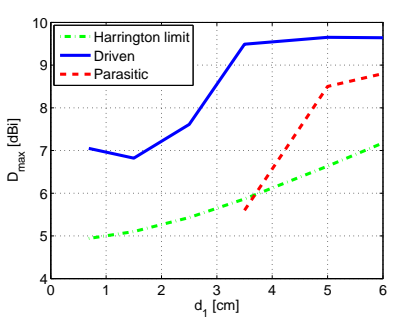

(c)

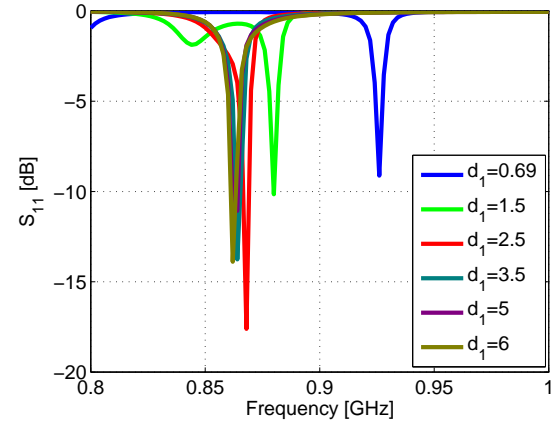

(b)

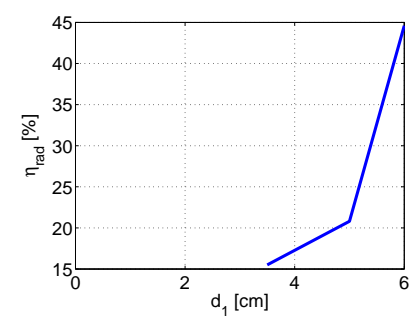

(d)
Fig. 1. Proposed array simulated parameters as a function of the inter-element distance. (a) Array geometry, (b) input reflection coefficient magnitude in $\mathrm{dB}$, (c) total directivity and (b) radiation efficiency.

A prototype of the antenna array for $d_{1}=6 \mathrm{~cm}(0.17 \lambda)$ was fabricated and measured (Fig. 2(a)). In this array, the second element is excited, the first is short-circuited, while the third one is loaded by $8.3 n \mathrm{H}$. Fig. 2(b) shows the antenna input reflection coefficient magnitude in $\mathrm{dB}$. As it can be noticed, the antenna has a simulated/measured resonance at $863 / 868 \mathrm{M} \mathrm{Hz}$ with a $S_{11}<-10 d B$ bandwidth of $1.7 / 5 \mathrm{MHz}$. The higher losses in the measurement may be attributed to the UFL cable used in measurement. Fig. 2(c) shows the antenna 3D total directivity radiation pattern. The figure shows a directive pattern with a directivity of $8.8 / 8.5 d B i$ toward z-axis. This directivity is about $1.4 d B$ greater than Harrington's normal directivity limit for an antenna with the same size factor 
$(k a=1.6)[12]$. The HPBW in $\mathrm{E}(\mathrm{XoZ})$ and $\mathrm{H}$ (YoZ) planes are respectively $72^{\circ} / 73.1^{\circ}$ and $64^{\circ} / 67.5^{\circ}$ and FBR is $5.8 \mathrm{~dB} / 4.1 \mathrm{~dB}$ (Fig. 3). The antenna presents a radiation efficiency of $34.7 \% / 37 \%$. Finally, Fig. 4 shows that the current on the first and third elements are on phase and they are out of phase compared to the second element. This is the condition for having three-element superdirective arrays with very small spacing.

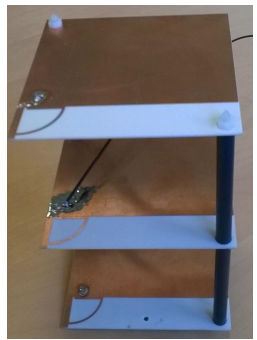

(a)

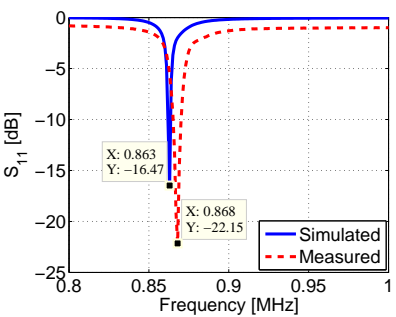

(b)

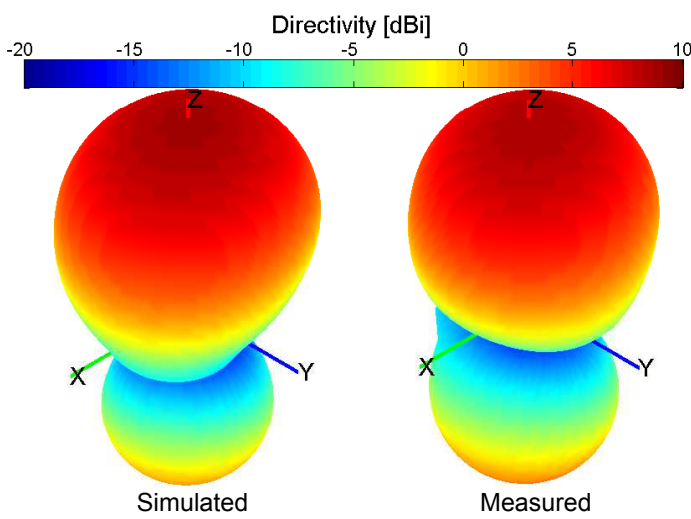

(c)

Fig. 2. Three-element array with $6 \mathrm{~cm}$ spacing simulated and measured parameters. (a) Fabricated prototype, (b) input reflection coefficient magnitude in $\mathrm{dB}$ and (c) 3D total directivity radiation pattern.

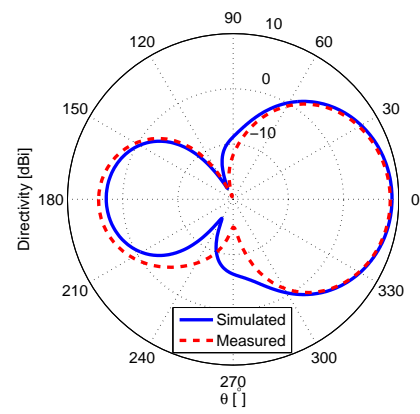

(a)

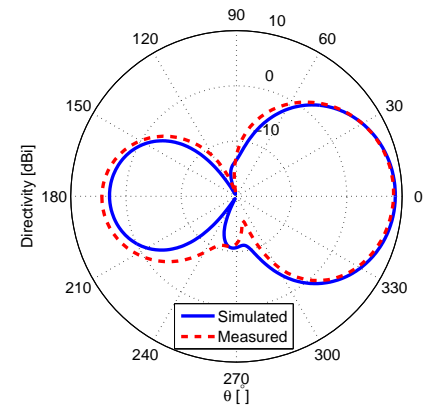

(b)
Fig. 3. Three-element array with $6 \mathrm{~cm}$ spacing simulated and measured parameters $2 \mathrm{D}$ total directivity radiation patterns. (a) E-plane, (b) H-plane.

\section{CONCLUSION}

In this paper, we investigated the design of a three-element stacked parasitic antenna array for UHF band. The tradeoffs between the antenna directivity, radiation efficiency, and dimensions were demonstrated. A prototype was fabricated and measure. The measured results were in a very good agreement with the simulated ones.

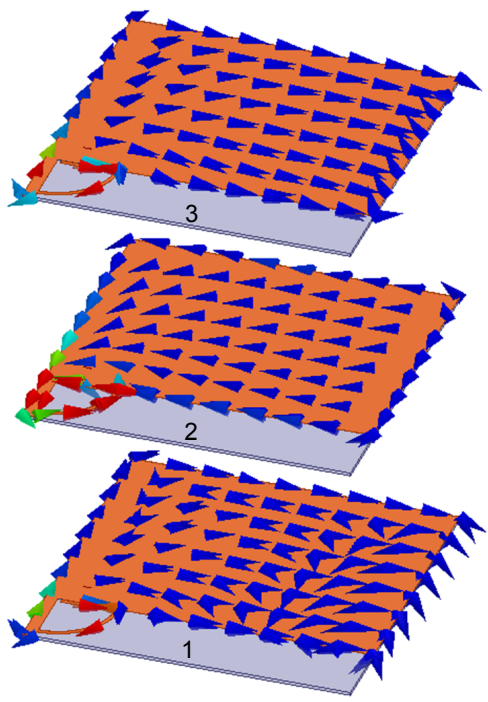

Fig. 4. Three-element array with $6 \mathrm{~cm}$ spacing simulated surface current distribution.

\section{REFERENCES}

[1] E. E. Altshuler, T. H. O’Donnell, A.D. Yaghjian, and S. R. Best, "A Monopole Superdirective Array", IEEE Transactions on Antennas and Propagation, Vol. 53, No. 8, pp. 2653-2661, August 2005.

[2] T. H. O'Donnell, and A. D. Yaghjian, "Electrically Small Superdirective Arrays Using Parasitic Elements", IEEE Antennas and Propagation Society International Symposium 2006, pp. 3111,3114, 9-14 July 2006.

[3] T. H. O'Donnell, A. D. Yaghjian, and E. E Altshuler, "Frequency Optimization of Parasitic Superdirective Two Element Arrays", IEEE Antennas and Propagation Society International Symposium 2007, pp. 3932,3935, 9-15 June 2007.

[4] S. Lim, and H. Ling, "Design of Electrically Small Yagi Antenna", Electronics Letters, Vol. 43, No. 5, pp. 3-4, 1 March 2007.

[5] A. D. Yaghijian, T. H. O’Donnell, E. E. Altshuler, and S. R. Best "Electrically Small Supergain End-Fire Arrays", Radio Science, Vol. 43, 2008.

[6] O. S. Kim, S. Pivnenko, and O. Breinbjerg, "Superdirective Magnetic Dipole Array as a First-Order Probe for Spherical Near-Field Antenna Measurements", IEEE Transactions on Antennas and Propagation, Vol. 60, No. 10, pp. 4670-4676, October 2012.

[7] P. Sharma, D. Arora, and H. Gupta, "Designing Superdirective Patch Antenna Array Using Metamaterial", International Journal of Engineering Research \& Technology (IJERT), Vol. 1, Issue 8, October 2012.

[8] A. Clemente, M. Pigeon, L. Rudant, and C. Delaveaud, "Design of a Super Directive Four-Element Compact Antenna Array Using Spherical Wave Expansion, IEEE Transactions on Antennas and Propagation, vol. 63, no. 11, pp. 4715-4722, November 2015.

[9] A. Haskou, A. Sharaiha, and S. Collardey, "Integrating Superdirective Electrically Small Antenna Arrays in PCBs", IEEE Antennas and Wireless Propagation Letters, doi: 10.1109/LAWP.2015.2425913.

[10] A. Haskou, A. Sharaiha, and S. Collardey, "Design of Small Parasitic Loaded Superdirective End-Fire Antenna Arrays", IEEE Transactions on Antennas and Propagation, vol. 63, no. 12, pp. 5456-5464, December 2015.

[11] ANSYS HFSS, Pittsburg, PA 15219, USA.

[12] R. F. Harrington, "On the Gain and Beamwidth of Directional Antennas", IRE Transactions on Antennas and Propagation, pp. 219-225, July 1958. 